\title{
PERABÉ, 2014-2015
}

Luiza Peixoto Baldan é artista visual, professora da EAV Parque Lage e doutoranda em Linguagens Visuais no PPGAV/EBA UFRJ. E-mail: info@luizabaldan.com

\section{Resumo}

São Paulo foi a primeira casa onde morei longe do mar, mas ouvi dizer que podia ser avistado ao sul da cidade. Foi assim que parti em busca de uma paisagem quase fictícia, percorrendo diferentes rotas que me levassem da capital paulista ao litoral, coletando as impressões em fotografias e textos. Deixei-me guiar por histórias e acasos até chegar a Santos, ao bairro Marapé (antigo Perabé), que em tupi significa "caminho do mar".

\begin{abstract}
Sao Paulo was my first house away from the sea, but I heard it could be seen somewhere south. That is how I started a quest to find an almost fictional landscape. By taking different routes from the capital to the coast, I have collected impressions in photographs and texts. I let myself be guided by stories and accidents until reaching the Marapé neighborhood in Santos (former Perabé), which in Tupi means "path to the sea."
\end{abstract}

Uma cidade ajuda a ler outra cidade.

Cidade é lugar de memória.

Para os viajantes, a cidade natal é a casa que se carrega na mala para facilitar a chegada em um lugar desconhecido.

A minha cidade natal é o mar.

Em qualquer saudade, em qualquer sonho, em qualquer pesadelo, o azul é o que se vê e a maresia é o que se sente.

Onde eu nasci tem mar. Para onde eu mudei tem mar.

E em cada porto que atraquei, deixei um pouco do porto de partida.

Então a casa é mar, em sua maleabilidade e insistência.

As águas se contaminam, se comunicam, levam e trazem.

Ainda crianças, quando mal sabemos ler a cidade, a escala das avenidas e prédios assusta. $\mathrm{O}$ mar intimida. Somos seres diminutos cercados por grandes massas e volumes que desde cedo nos ensinam sobre hierarquia e o viver em sociedade. Conforme crescemos, a cidade também cresce, mas a percebemos menor.

O mar é o único que não muda com o tempo.

Todas as cidades em que morei têm mar, menos uma. A cidade sem mar é a única que não para de se agigantar.

Andar na cidade sem mar é se perder e se achar no labirinto urbano, é chocar-se contra torres e morros e se esvair na poluição.

Sobrevoar a cidade sem mar é se perder de vista, é chocar-se contra torres e morros e se esvair na poluição. É ser persistente e olhar através para encontrar o mar.

O horizonte da cidade sem mar é o tiritar das lâmpadas incandescentes que se sobrepõem à distância.

Da cidade sem mar procuro o mar.

Remonto às rotas daqueles que subiram do mar.

Encosto na muralha.

Encosta na costa.

Por que virar as costas para o mar?

Revista Escrita

Rua Marquês de São Vicente, 225 Gávea/RJ CEP 22451-900 Brasil

Ano 2017. Número 23. ISSN 1679-6888.

escrita@puc-rio.br 
De costas para a costa na capital da solidão e sua perfeita sanidade.

Da cidade sem mar avisto o mar.

O Planalto de Piratininga, Inhapuambuçu e seus heróis providenciais, embrenhados e destros. A Itaecerá partida. A promessa do Peabiru e os Tupiniquins.

Não é serra, é escarpa. Tudo será construído no caminho, entre aroeiras, vias e desvios. A angústia da pré-viagem, andradiana, e a satisfação de correr mundo, de nadar mundo. Nas leis do mar, o maior tem sempre a vez.

Via a água na foto e perguntava.... será a baia perto do aeroporto?.....melhor rir. E meu orgulho aumenta por sua garra e determinação....num hotel de luxo trabalhando quando há uns anos atrás estávamos humildemente pedindo guarida num hotel em Ipanema.

Não posso deixar de contar que quando corria do Leblon até o Arpoador, era justo aí que tomava um banho maravilhoso...na volta tomava o último já no Leblon.

Voltava revigorada...

Ah sim, fiz tudo novamente depois

Bate saudade.... fico a divagar.

Mas são lembranças boas.

O seu mar eu sei de cor. A caminhada matinal também, ainda que você não se lembre que eu perseguia a sua sombra, firmando a minha pegada sobre a sua antes do mar apagar. Você apertando a minha mão, beliscando meus dedos com a aliança, depois que o pivete arrancou a correntinha de ouro do seu pescoço. O seu céu e o meu fotografados da mesma varanda com algum tempo de diferença. Imagem temporã como eu. Imagem daquilo que é imutável desde o princípio das horas.

dizia, meu mar !...diante de tanto azul!

Na falta do mar há céu.

Quando os azuis se sobrepõem e já não faz mais sentido saber quem está por cima ou por baixo da discreta linha do horizonte.

O meu mapa é uma grande recorrência sua, Atlântico. Ainda feto nadava na barriga da mãe. Sou marmífera. Eu queria mesmo era ter nascido na sua beira, no algodoal mais branco do mundo, mas isso seria suicídio. Eu bem que tentei. Em solavancos, sigo o seu rastro em viagens partidas, como tantos tamoios, tijucos, tropeiros e piratas o fizeram de Cabo Frio a Santos.

Caminho do mar. Caminho para o mar. Caminho... Camão onde deitar por horas a fio olhando as estrelas, onde só lhe dão sonhos. Travessia de silêncio profundo, onde a luz cega e as plantas estalam com o vento cortante. Brisa uivante, transversal, que dá dor de 
ouvido. O quentinho do meio-dia assolando o cucuruco branco. Agachar e rolar na areia esvoaçante que espeta a pele e se transfere para outro lugar. Divagar entre as dunas. Ser duna.

Em 21 de janeiro deram à vela e se aproximaram mais da terra, das praias abafadiças e tristonhas. Piaçaba. Naus, um galeão e duas caravelas, uma delas chamada Rosa. Essas ilhas têm uma ilhota entre elas e também há cobras e dragão. Ilha que virou península. Em 21 de janeiro a fragata de caiçaras se perdeu no mar.

Lugar de secar peixe

Lugar de ver o mar

Lugar de desembarcar

Lugar que se vê de longe

De todos os caminhos possíveis, escolho o meu. Tantos trajetos refeitos, pé ante pé sem a menor pista. Rotas automáticas impulsionadas por um fluxo qualquer imposto não sei por quem. E de tanta repetição algo se faz presente. Um canto alto e monótono que interrompe inesperadamente a solidão muda do caminhar frequente. A pedra em que tropeça e desperta para o que há ao redor. O alarde e o reconhecimento.

A paisagem é testemunha do passado. A idade do lugar, a idade nossa. Onde termina o onde e começa o eu se estamos embrenhados um ao outro? Experiência da ordem da linguagem. A língua brasílica e a língua-geral. Entre os mitos, os contos e os espelhos, os guaianás, os tupis, os escravos, os mamalucos e os favelados, na companhia de jesus. Experiência da ordem da imagem, do visível e do indizível.

Território mediado. Não há terra prometida. O Tietê corre para longe do mar. Elevatória de traição.

Qual o fim de tudo o que entra no seu olho? Poeira, cílios, imagens... Chorar é chover. É alagar. Vereda limosa e escorregadia.

A margem elástica, a ondinha mole.

O lugar limite entre o seco e o molhado.

O espaço-entre.

O instante que antecede o arrepio da pele.

Sentir a areia dura derreter.

A terra vista, o porto, o pouso.

Ponto de encontro entre o que chega, o que parte e o que espera.

Pangeia repartida em oceanos que margeiam ínvios territórios. 
Marinheiros, náufragos e degredados atracam na ponta da praia e seguem a linha do trem, pelo caminho seguro que afasta do mar. Pouco a pouco, um a um se aparta. Como os ascendentes que chegaram em buques e rumaram na Inglesa pela Serra Velha até Jundiaí.

De ser subterrâneo a ser subcutâneo, procurando nas vísceras o saber da memória mais profunda. Antepassados estendidos no coração.

Gamboa. Delongas. Mirongas. Milongas.

Mar tão largo.

Posso amar quem não conheço?

Uma história como essa só é possível construir com excelência, liderança e trabalho em equipe.

Pessoas sobem e descem, despreocupadas dos sacrifícios. Rosa dos ventos embaralha tudo de poeira e areia, bagunçando início e fim. As garatujas do saci me levam do sertão ao mar. Letargia e cateretê. Persigo o cinza que será lançado ao mar quando por fim encontrá-lo. Morrer no mar ou longe do mar. Marrer-de-si.

Penetro o mistério da alta muralha que fecha os mangues do litoral. Afasto-me do cenário de costume. Montanha nebulosa, gigante pela própria natureza hostil. Sertão ignoto estendido pelo curso dos rios sombrios.

O cheiro do mar vem não sei de onde, mas entorpece. Nada além de matagal. As pegadas da maresia são o líquen nos troncos e sinalizam para o céu. O sal poliniza. Mais adiante, pela biquinha d'água, nascente do mar evaporado, tudo flui e Iara me lava. No caeté, o curupira guardião fantasma, sussurro de sábio e sabiá. A coruja curucutu disfarçada de assombração, de velho do saco, mareada pelo canto da mati-taperê.

A breve pausa para sentir o gosto do araçá e perceber a cor do sanhaço. Águas são muitas, infinitas.

O som telúrico repetitivo do caminho contra o pé. O chocalho da pegada que chacoalha o mato onde a cobra chocalha. Tudo se repete. Oxumaré.

De um caminho que começa no verão e termina na primavera, na molícia do clima. Passar de um lado a outro entrecruzando as estações. Rios e mangues. Caminhar no ar, semicerrar os olhos para os verdes da serra, das sendas. Melancólica colina isolada sobre a maresia, sobre as saudades marítimas. Sal-dades. A floresta vem de encontro e os saçurás aquecem a pança roliça com aguardente de cambuci. 
A maçaneta pegajosa e o cadeado enferrujado. Barril com água salobra. A geladeira carcomida e a porta emperrada. O espelho embaçado e as toalhas cheirando a mofo. A fruta sumarenta e a venenosa que parece pitanga. Arapucas e gaiolas. A janela e o vento em forças opostas. O anjo-caído e as bolinhas laranjas dos fios elétricos. Lá longe a calmaria das águas de Iemanjá, mãe da vastidão e das revoltas líquidas.

Levantar vôo na curiosidade do desconhecido. Nômade e estrangeiro na própria terra. Primeira estrada a ter calçamento, a ser pavimentada. As famosas curvas da música do Rei. Piaçaguera Velha • Caminho do Padre José • Itutinga-Pilões • Calçada do Lorena • Estrada da Maioridade - Estrada do Vergueiro - Estrada Caminhos do Mar - Estrada Velha de Santos • Via Anchieta • Rodovia Imigrantes • Rua da Glória, primitivo caminho do mar.

Sempre empreendendo longas viagens e ignorando prazos de ausência.

O caminho do mar daqui era um obstáculo, uma muralha íngreme que subiam engatinhando ou agarrando no mato. Era o centro do trampolim para mergulhar no sertão e correr do mar. A serra isola. O caminho do mar de lá era uma picadinha no meio da restinga, com vento rasteiro, que sugava até o topo da duna. Correr pro mar. A praia junta. O caminho do mar do além-mar era uma vastidão de possibilidades. Correr com o mar. O oceano leva. O mar tão perto, mas tão longe...

Turva curva da morte.

O barco no topo da montanha.

Água de escorregador.

A cidade opaca sob a cerração.

Sonhar com cobra pode ser um monte de coisa. Sonhar com teia de aranha é indício de viagem próxima. Aranhas descendem de aracnídeos aquáticos. A teia é um caminho que ziguezagueia e gira em torno de si mesmo como uma cobra. Tear um sonho circular de fios úmidos e cruzados. Sonho que morde o próprio rabo. Armadilha de baixa isolação. Circo lar. A seda da arquitetura reflete ultravioleta. Presa e predador. Frágil e flexível. Autorreflexiva.

Do lugar de onde se vê o mar sempre há névoa, um algodão-doce acinzentado de friagem e garoa. É do fundo do céu que vem o martírio de água salgada com uma pitada de doce. Doce de cana, soro caseiro. Paisagem encharcada. Avesso do sonho das coisas voltadas para o mar. Mar-si-lac. Mar-apé. Nomes próprios.

Do vale ao clímax à depressão ao nível do mar.

Onda topográfica. 
O marrano e a índia.

Mar e terra.

Adão e Eva da baixada.

Duas ruas paralelas.

Há mares que não chegam ao oceano. O daqui é mar mutante acorrentado a luas contra o oceano estável de horizonte eterno. Maré que enche e vaza. Ondas transversais que propagam energia. Objetos que boiam, sobem e descem sem sair do lugar. O que muda lá longe a gente não vê. De perto, o que muda, arrebenta.

O oceano é a vastidão por excelência. Abissal. Rota de fuga.

Será que foi por ali que você escapou? Nunca soube nadar, mas todos os dias boiava na beirinha daquela água transparente exibindo o esmalte vermelho das unhas dos pés submersos.

Do passado anfíbio, mãos e pés que rastejam, que enrugam. Anticorpos que sobrevivem em solução marinha. Memória do que um dia foi nossa vida no mar.

O que é puramente visível, é insuficiente. Esse monte de azul inventado. Maravilhamme as coincidências.

Em um fluxo desancorado, aprendendo a se desapegar aos poucos, discorrendo sobre pedras para desanuviar os pensamentos turvos. Largar a ostra para ser vento. Tatuí que não se deixa aprisionar em garrafas pet. Desejos que não seguem as correntes do mar.

Hei de ficar comovida, contemplando, contemporizando como você me ensinou. Por vezes codaquizando a paisagem em movimento, inventariando intervalos daquilo que vi e me pareceu.

\section{Omnia vincit amor subditorum}

A cordilheira vista do mar. Eis a fortaleza. O planalto, terra de promissão, caminho de Sísifo. A cidade da memória e a memória da cidade. A memória que empresta identidade e nostalgia. Piaçaguera Velha, última aldeia Tupi-Guarani do Atlântico, gentrificada.

Paisagem muda. Paisagem que não muda. Paisagem que ensurdece.

Dos pesadelos adolescentes, a onda gigante que surge no mar tranquilo. Taquicardia. Mergulhar, agarrar na areia mais profunda e ser arrebatada pela tremenda espuma que destrói tudo a quilômetros. Soluçar intensamente por cada desaparecido. Dos pesadelos 
adultos, a onda gigante que surge no mar tranquilo. Taquicardia. Mergulhar, suavemente agarrar na areia mais profunda e deixar a tremenda espuma passar. Emergir e perceber que tudo continua como era antes.

Esperar e jogar linha. Lugarejos pioneiros que se amiudaram com o tempo. Tão diferentes da cidade sem mar.

O mar das gaivotas que amam.

O repertório de cidades desestranha tudo. Piratininga $\bullet$ Ipanema $\bullet$ Humaitá $\bullet$ Paquetá Nilo Peçanha. Jair e Tito, Marlene e Ivo. A paisagem torna-se amável.

A cidade com mar e suas lendas de fantasma, vulcão e dragão d'água. Monstro marinho diabólico, Ipupiara. Não eram flibusteiros do além-mundo, eram corsários hereges e luteranos, ministros das trevas licenciosos. A cidade com mar tem suas miudezas e seus superlativos. O cemitério onde os cadáveres repousam sobre o mar. Os prédios que inclinam pela maresia. Tantos mais e tantos menos. Tanto mar.

Lagamar, ubás, pirogas, canoas de troncos de árvores, loides e brasileiros.

De caminho ao mar, encontro sem querer o lugar dos sonhos da dona do caderno que achei no lixo quando era criança. Passear pelas ruas sem entender o que era tão especial ali para aquela menina. Entender o quão relativo é o espacial.

Holiday é o Balança Mas Não Cai da primeira cidade do Brasil.

Impossível haver um caminho que ninguém caminha. Pisar o caminho de tantos. O que vem depois de mim passou adiante de mim, porque existia antes de mim. Milenar trilha de pé posto.

Pedra de macadame sob a serra de paliteiro. Manacá-da-serra é branco quando nasce, rosa quando cresce e violeta quando morre. Travessa das Violetas número 100 casa 8. Endereço que não existe mais. Quaresmeira da neblina densa.

A mata do oceano sufocada pelas turbinas da cidade grande. Aspérrima. Sai nativa, entra embaúba. O quilombo rio e o corredor dos escravos fugitivos, resistentes. Caminho de Cazuza. O cheiro da onça é o refogado da hora do almoço. Memória de zoológico para se familiarizar com a mata.

Tudo o que gira em torno da pedra, que vive e existe porque há pedra, que cala porque há perda. Desentupir as ventas com água marinha, mesmo não sendo mais possível respirar dentro d'água. 
É março.

$\mathrm{O}$ farol e o belvedere.

O pontal e o atalaia.

Onde o rio encontra o mar.

$\mathrm{Na}$ orelha da praia, o presságio, o soluço. Ouvido labirinto absoluto. Quando silêncio, as batidas do coração. A respiração prolongada que se mistura ao ronronar das ondas. $\mathrm{O}$ alento úmido, cíclico, sincronizado, ressonante. Pele russa de sal seco. A superfície molenga da água. Nado e mar nada.

Alguns trechos do texto foram inspirados em leituras diversas e plurais como:

Carta de Pero Vaz de Caminha a EI Rei D. Manuel I. São Paulo: Dominus, 1963.

DE ABREU, J. Capistrano. Caminhos Antigos e Povoamento do Brasil. São Paulo: Livraria Briguiet, 1960.

DONATO, Hernâni. Pateo do Collegio: Coração de São Paulo. São Paulo: Ed. Loyola, 2008.

Evangelho de João (1, 1-18).

http://www.novomilenio.inf.br/santos/h0100b40a.htm

http://revistapesquisa.fapesp.br/2015/01/19/alem-do-butim/

PORCHAT, Edith. Informações históricas sobre São Paulo no século de sua fundação. São Paulo: Ed. Iluminuras, 1993.

PRADO, Paulo. Paulística, etc. / 4. ed. rev. e ampl. por Carlos Augusto Calil. São Paulo: Companhia das Letras, 2004.

STADEN, Hans. Duas viagens ao Brasil: arrojadas aventuras no século XVI entre os antropófagos do novo mundo. São Paulo: Publicações Sociedade Hans Staden, 1942.

TOLEDO, Roberto Pompeu de. A capital da solidão: Uma história de São Paulo das origens a 1900. Rio de Janeiro: Objetiva, 2003. 

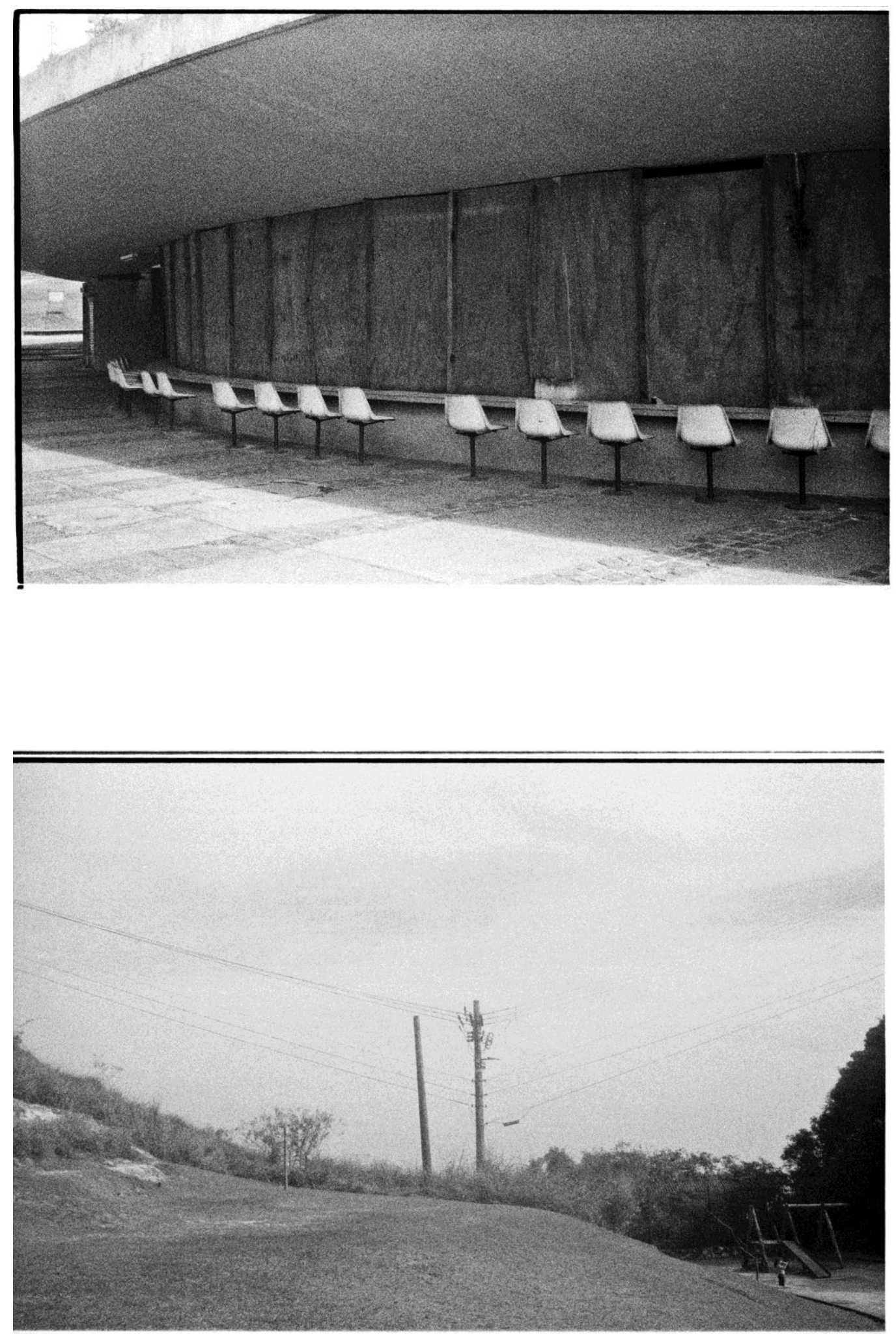

Revista Escrita

Rua Marquês de São Vicente, 225 Gávea/RJ CEP 22451-900 Brasil

Ano 2017. Número 23. ISSN 1679-6888.

escrita@puc-rio.br 

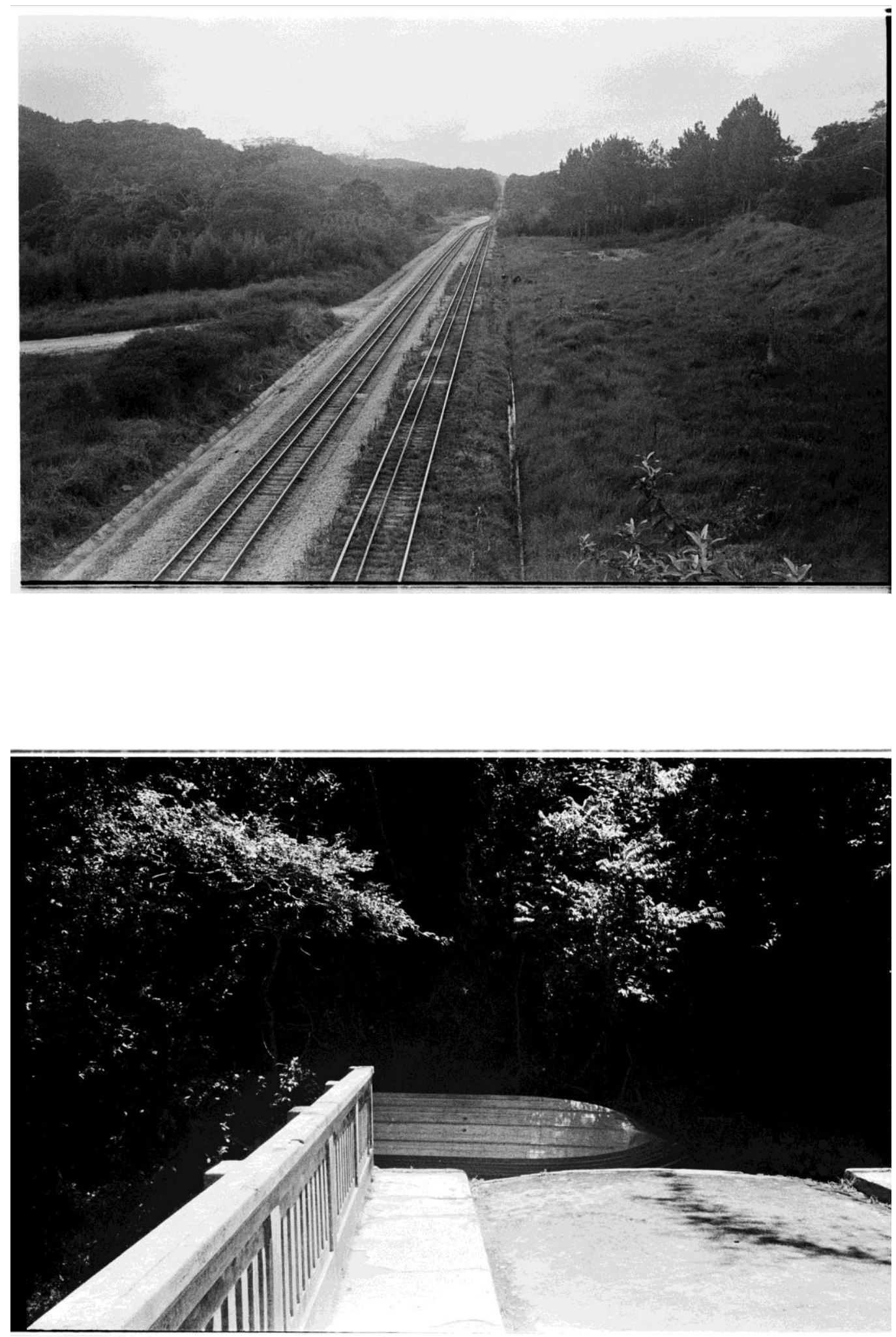

Revista Escrita

Rua Marquês de São Vicente, 225 Gávea/RJ CEP 22451-900 Brasil

Ano 2017. Número 23. ISSN 1679-6888.

escrita@puc-rio.br 

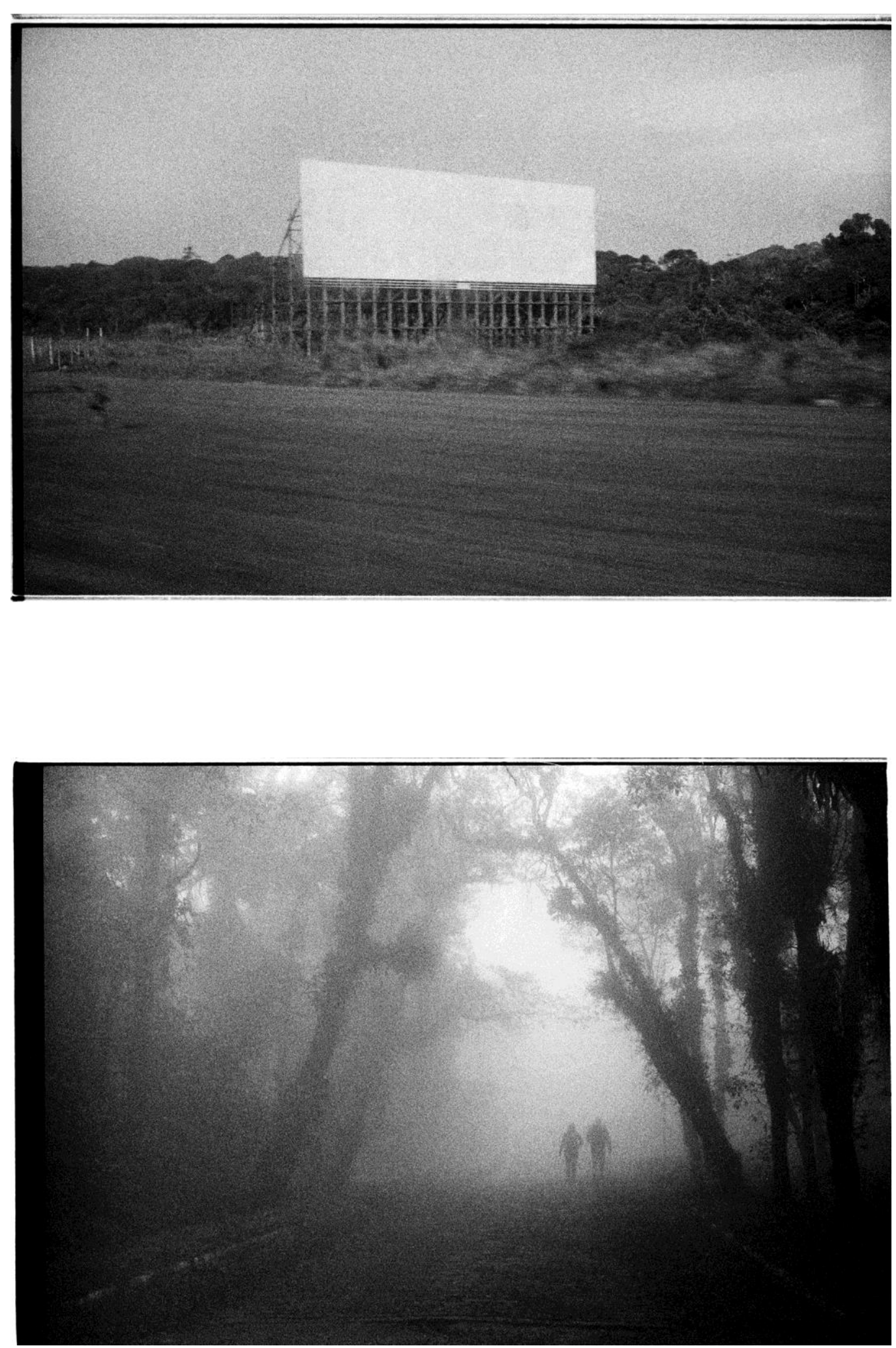

Revista Escrita

Rua Marquês de São Vicente, 225 Gávea/RJ CEP 22451-900 Brasil

Ano 2017. Número 23. ISSN 1679-6888.

escrita@puc-rio.br 

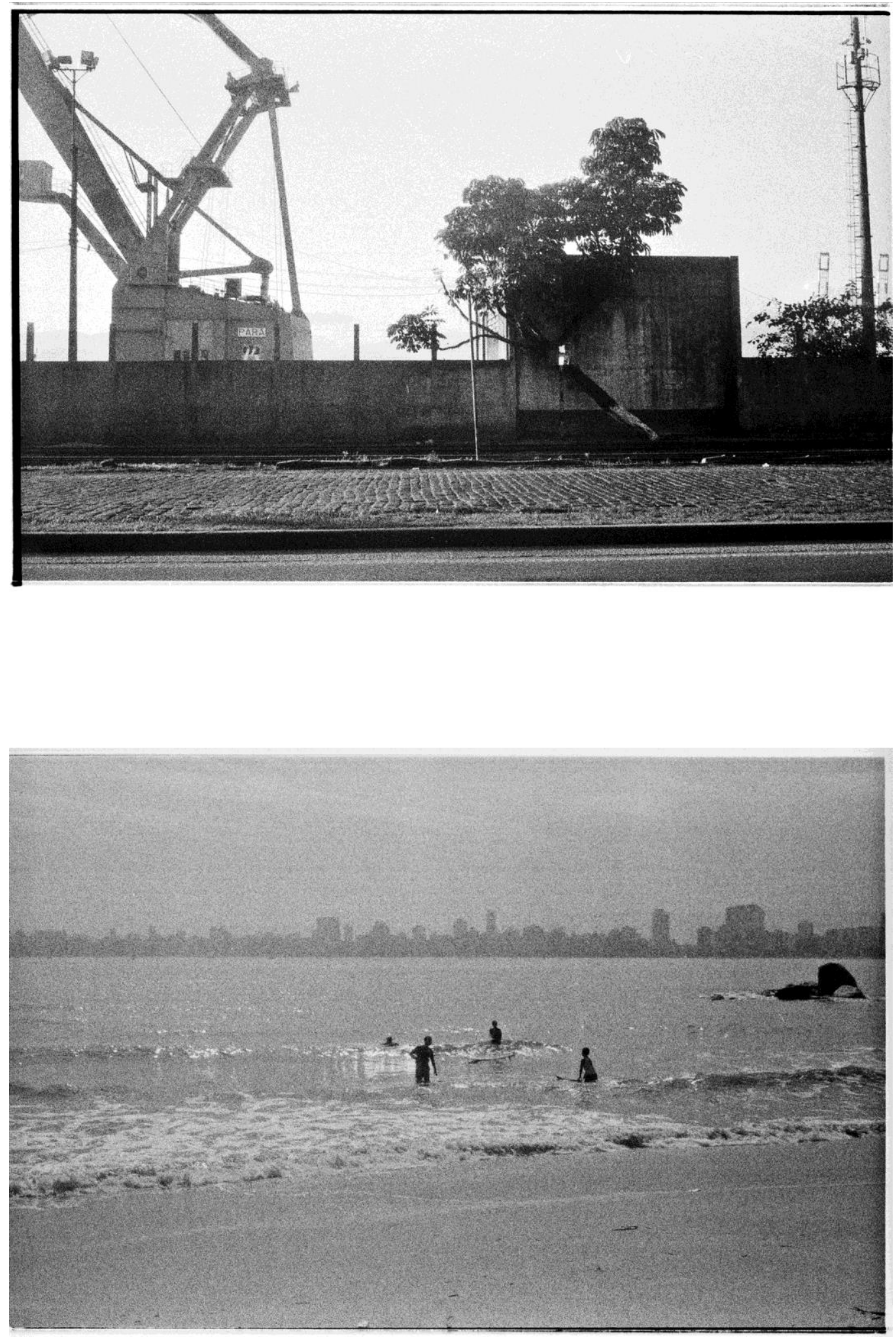

Revista Escrita

Rua Marquês de São Vicente, 225 Gávea/RJ CEP 22451-900 Brasil Ano 2017. Número 23. ISSN 1679-6888.

escrita@puc-rio.br 